\title{
Design, prototyping, and testing of a compact superconducting double quarter wave crab cavity
}

\author{
Binping Xiao, ${ }^{1}$ Luís Alberty ${ }^{3}$ Sergey Belomestnykh, ${ }^{1,2}$ Ilan Ben-Zvi, ${ }^{1,2}$ Rama Calaga, ${ }^{3}$ \\ Chris Cullen, ${ }^{1}$ Ofelia Capatina, ${ }^{3}$ Lee Hammons, ${ }^{1}$ Zenghai Li, ${ }^{4}$ Carlos Marques, ${ }^{1}$ John Skaritka, ${ }^{1}$ \\ Silvia Verdú-Andres, ${ }^{1}$ and Qiong $\mathrm{Wu}^{1}$ \\ ${ }^{1}$ Brookhaven National Laboratory, Upton, New York 11973-5000, USA \\ ${ }^{2}$ Stony Brook University, Stony Brook, New York 11794, USA \\ ${ }^{3}$ European Organization for Nuclear Research (CERN), CH-1211 Geneva 23, Switzerland \\ ${ }^{4}$ SLAC National Accelerator Laboratory, Menlo Park, California 94025, USA
}

(Received 23 December 2014; published 28 April 2015)

\begin{abstract}
We proposed a novel design for a compact superconducting crab cavity with a double quarter wave (DQWCC) shape. After fabrication and surface treatments, this niobium proof-of-principle cavity was tested cryogenically in a vertical cryostat. The cavity is extremely compact yet has a low frequency of $400 \mathrm{MHz}$, an essential property for service in the Large Hadron Collider luminosity upgrade. The cavity's electromagnetic properties are well suited for this demanding task. The demonstrated deflecting voltage of 4.6 MV is well above the required 3.34 MV for a crab cavity in the future High Luminosity LHC. In this paper, we present the design, prototyping, and results from testing the DQWCC.
\end{abstract}

DOI: 10.1103/PhysRevSTAB.18.041004

PACS numbers: 41.85.Ct, 25.75.Gz, 74.25.nn, 84.40.-x

\section{INTRODUCTION}

Devices that change the transverse motion of particle beams are used widely in accelerators. The deflecting systems provide a kick to the center of mass of particle bunches, whereas crabbing systems kick the head and tail of the bunch in opposite directions, with a net-zero kick to its center of mass. Radio-frequency deflection systems are used both as beam choppers [1-3] and beam separators [4-8]. Some examples of applications employing crabbing systems are ultrashort beam pulse generators [9-11], in measuring longitudinal and transverse phase space and bunch length [12-14]; they also are invaluable for ultrashort femtosecond diagnostics [15-18] and "crab crossing" for head-on collision in particle colliders [19]. The concept of crab crossing, which utilizes a transverse rf field excited in a resonator called a crab cavity, was proposed by Palmer [20] and first implemented in the electron-positron collider KEKB [21]. In collider applications, where a large transverse kick must be delivered within the limited space available near an interaction point (IP), superconducting $\mathrm{rf}$ (SRF) crab cavities are employed.

LHC at CERN is an energy-frontier machine for highenergy particle physics, with energies up to $7 \mathrm{TeV}$ per nucleon. The High Luminosity upgrade of the LHC (HL-LHC) includes installing new interaction region (IR) quadrupoles [22] to reduce the beam's size at the

Published by the American Physical Society under the terms of the Creative Commons Attribution 3.0 License. Further distribution of this work must maintain attribution to the author(s) and the published article's title, journal citation, and DOI. interaction points. This demands large crossing angles to alleviate the effects of beam-beam interaction. Here, an implementation of the crab-crossing technique [23-29] can be used to modify the angle at which bunches collide, and hence, would complement the upgraded IR quadrupole to maximize the LHC's luminosity.

The limited space available surrounding the ATLAS and CMS detectors, at IP1 and IP5, respectively, limits the dimensions of the crab cavities. An upper limit to the frequency is set to minimize nonlinearities of the crab kick given to the bunches. This has resulted in a relatively low resonant frequency of the HL-LHC crab cavities at $400 \mathrm{MHz}$. Currently, there are three designs of compact crab cavities that are potential candidates [24-29]; the double quarter wave crab cavity (DQWCC), the subject of this article, is one of them.

The LHC crab cavity project is divided into three phases. The first one aims to validate the cryogenic performance of proof-of-principle (PoP) cavities. They must demonstrate a deflecting voltage of $3.34 \mathrm{MV}$ per cavity. The second phase comprises the design and prototyping of a pair of fully dressed cavities that will be tested with the beam in the Super Proton Synchrotron (SPS) at CERN in 2017-2018. The third phase is dedicated to designing, manufacturing, and installing the crab cavities in the LHC, with four cavities per beam at each side of the IP, i.e., 32 cavities in total plus spare ones.

Quarter wave resonators (QWRs) are widely used in particle accelerators. The first superconducting QWR for ion acceleration was proposed by Ben-Zvi and Brennan in 1983 [30]. Since then, QWRs have been employed successfully in many low $\beta$ linacs [31-35]. In recent years, these cavities found new applications in high $\beta$ 
accelerators, such as those described in [36-40]. The QWR first was proposed as a deflecting or crabbing cavity by Ben-Zvi [41,42]. This design eventually evolved into a symmetric double quarter wave structure [26]. Compared to the conventional squashed elliptical cavity [21], the DQWCC is very compact, and its crabbing mode is the lowest resonant frequency, $f_{0}$, of the cavity. No lower order mode (LOM) or same order mode (SOM) exists in this structure, and the first higher order mode (HOM) is well separated from $f_{0}$ by about $f_{0} / 2$ due to the large capacitance. In this article, we describe the design, fabrication, and our results from testing the PoP DQWCC, built as part of the HL-LHC upgrade.

\section{CAVITY DESIGN}

\section{A. Cavity rf design}

A similar design of a normal-conducting cavity was proposed by Krawczyk [43] for low $\beta$ linacs. The DQWCC is the first SRF cavity design of this kind, in particular for high $\beta$ applications. The cavity, shown in Fig. 1, can be considered as two quarter-wave resonators sharing a load capacitor, thus dubbed a double quarter wave cavity. At the fundamental mode, there is a transverse electric field between the capacitor's two plates, offering the crabbing voltage when the beam passes at an appropriate phase.

Figure 2 shows an envelope of the cavity. The envelope, in particular the cavity's waist and height, along with all necessary ports, is optimized to fit the size limit of IP1 and IP5 in the LHC for both crabbing directions, as depicted in Fig. 3. Figure 4 illustrates the field distributions inside the DQWCC. The magnetic field of the fundamental mode is concentrated in the coaxial area. The waist of the cavity provides clearance to the second beam pipe for a vertical kick. The height of the cavity is restricted so that it is short
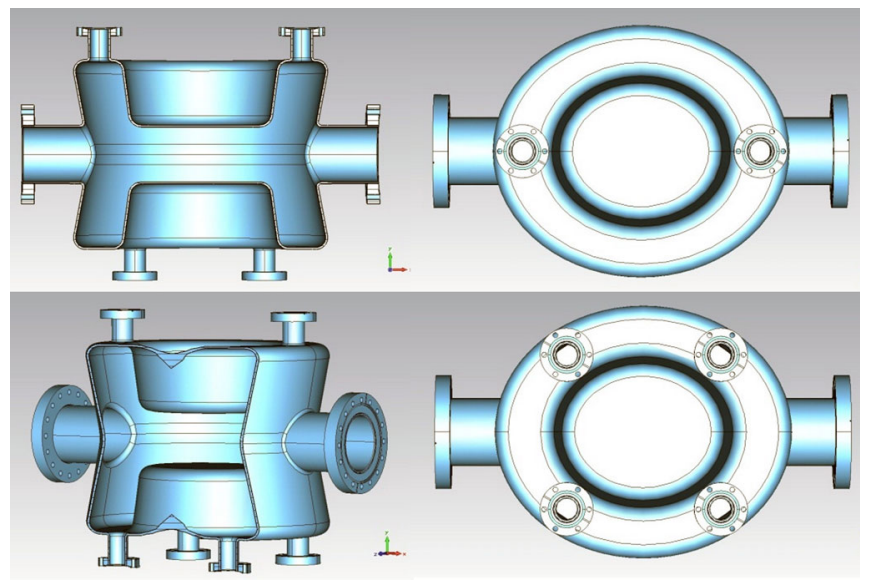

FIG. 1. Geometry of the DQWCC. Top left: front sectional view. Top right: top view. Bottom left: front left sectional perspective view. Bottom right: bottom view.
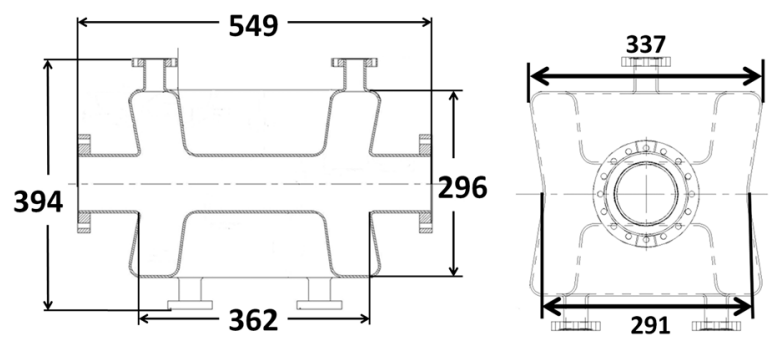

FIG. 2. Envelope of the DQWCC. Left: front sectional view. Right: left sectional view. All dimensions are in $\mathrm{mm}$.

enough to allow clearance for the second beam pipe for horizontal kick, as shown in Fig. 3(b).

Compared to the former version of the quarter wave cavity [25], the DQWCC is optimized to cancel the on-axis accelerating (longitudinal) field; it also reduces the overall nonlinearity of the deflecting voltage as a function of the offset [26] from the symmetry introduced by changing from a quarter wave to a double quarter wave resonator. The field's nonlinearity, caused by the axial asymmetry of the cavity, is characterized by its multipolar expansion coefficients as described in Refs. [44,45], with $b_{3}=1070$, $b_{5}=-1 \times 10^{5}, b_{7}=7 \times 10^{6}$. The other components are zero for the notation used in [44]. These numbers are well below the requirements specified in [45].

Table I lists the key rf parameters of the DQWCC using CST Microwave Studio with $>500,000$ tetrahedral meshes. Besides the two beam pipe ports, six extra ports are located on the top and bottom, with two on one top and four on the bottom, as shown in Fig. 1. These ports are designated for a fundamental power coupler (FPC), a rf pickup (PU) probe, and higher order mode couplers.

\section{B. Mechanical design of the cavity}

Based on the safety requirements at CERN [46,47], with a relief valve attached to the cryogenic test dewar set at 1.5 bar, the cavity must pass a proof test with a maximum pressure of 2 bar outside the cavity, and a vacuum inside it. The safety factor applied to the relevant material properties is 1.05 , that being the maximum allowable stress derived by the yield strength divided by the safety factor. The failure mode considered for the presented assessment of strength is gross plastic deformation: The maximum allowable stress of high RRR niobium, the material that the cavity is made
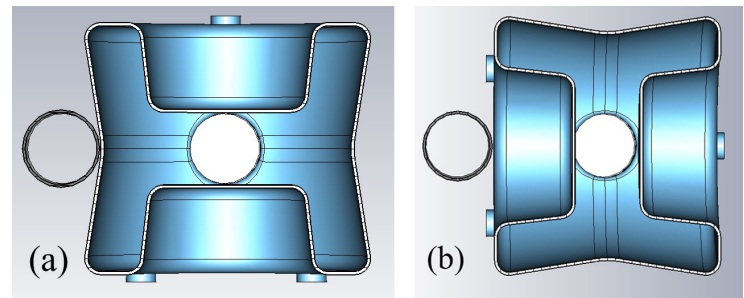

FIG. 3. DQWCC with adjacent beam pipes: (a) For the vertical kick scheme, and (b) the horizontal kick scheme. 


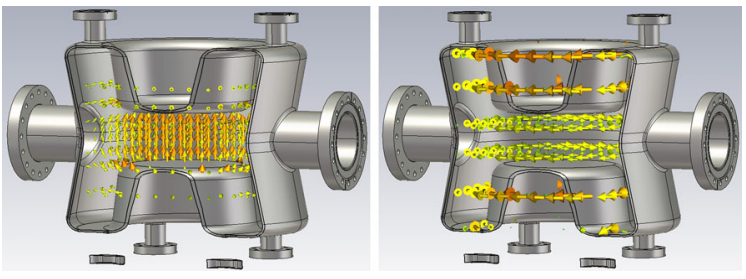

FIG. 4. Electric (left) and magnetic (right) field distributions inside the DQWCC.

of, is $70 \mathrm{MPa}[48,49]$. We used software ANSYS for analyzing stress and deformation, with a $2 \mathrm{~mm}$ mesh size for all simulations. Gravity was considered during simulations. During the tests, the cavity was positioned in a dewar with the axis of the beam in vertical direction.

The above-mentioned 2-bar difference in pressure makes the two capacitive plates move closer, and the region of the high magnetic field to deform, so generating high stresses therein. The standard niobium sheets come in different thicknesses varying from 2.8 to $4.0 \mathrm{~mm}$. If a 3-mm-thick niobium were used, the maximum total deformation of $1.2 \mathrm{~mm}$ would be at the center of the capacitive plate, and the maximum stress intensity of $150 \mathrm{MPa}$ would be located in the area of the magnetic field, exceeding niobium's maximum allowable stress. We chose 4-mm-thick niobium sheets to lower the maximum intensity of stress on the cavity with the beam pipes made of niobium tubes with 2.8-mm-thick walls. In the simulations, we accounted for a reduction of $0.21 \mathrm{~mm}$ in thickness resulting from treating the cavity's surface. However, even with thicker walls, the mechanical stress on the cavity still is too high.

The cavity is reinforced and supported by holding the two capacitive plates with a dedicated grade 2 titanium frame made of titanium bars, 2 in wide and 0.5 in thick, as shown in Fig. 5. Four niobium bars were electron beam welded to the capacitive plates. Then, the serrated surfaces of the titanium plates were bolted to the niobium bars, with the aid of another titanium bar with serrated surface on the other side of each. Table II lists the properties of niobium and titanium with data taken from Refs. [48,50].

The simulation model was modified to be symmetric along the vertical symmetry plane, and half of the model was used, so to reduce the calculation time.

TABLE I. Key rf parameters of the double quarter wave crab cavity.

Fundamental mode frequency $f_{0}[\mathrm{MHz}]$ 400

Nearest HOM frequency $f_{1}[\mathrm{MHz}]$

Deflection voltage $V_{t}[\mathrm{MV}]$

$R_{t} / Q$ (fundamental mode) $[\Omega]$

Geometry factor $[\Omega]$

Peak surface electric field $E_{\text {peak }}[\mathrm{MV} / \mathrm{m}]$

Peak surface magnetic field $B_{\text {peak }}[\mathrm{mT}]$

Residual accelerating voltage $V_{\text {acc }}[\mathrm{kV}]$

Stored energy $[\mathrm{J}]$
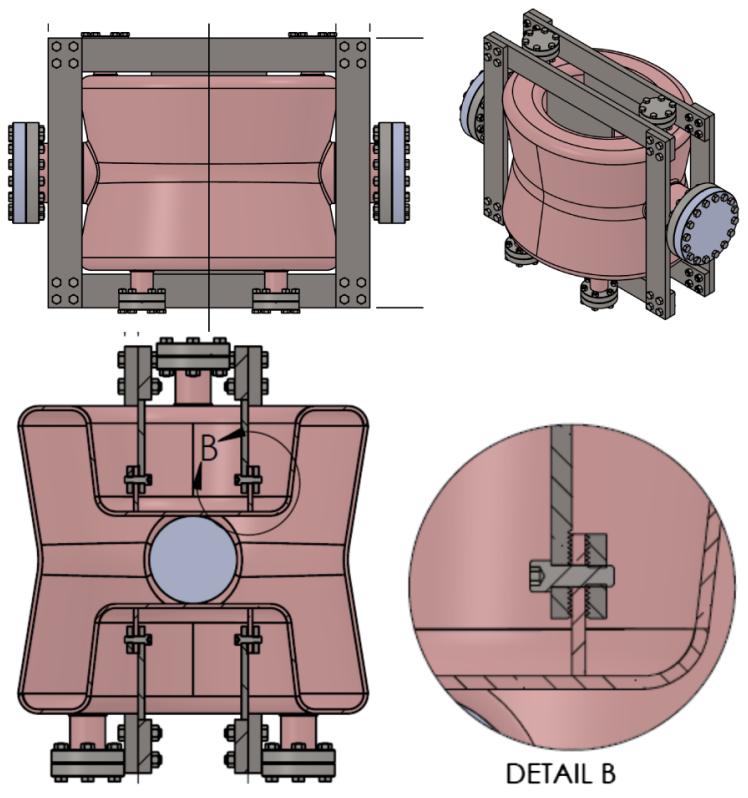

FIG. 5. Geometry of the PoP DQWCC with the titanium stiffening frame. Top left: front view. Top right: front left perspective view. Bottom left: left sectional view. Bottom right: detailed view of bottom left.

The maximum deformation due to a pressure load of 2 bar was around $0.5 \mathrm{~mm}$ for the cavity with a stiffener, located at the center of the capacitive plates. The maximum stress, $230 \mathrm{MPa}$, was found on the titanium stiffening frame, while the highest stress on the cavity was $67 \mathrm{MPa}$, below the maximum allowable stress of niobium.

\section{Multipacting}

Multipacting is the effect of an electron avalanche due to the resonant multiplication of secondary electrons. It absorbs rf power, hence limiting the power available to excite the fields in a cavity [51], and so causing the quality factor to decline, and limiting the maximum gradient in the cavity. Multipacting depends on the yield of secondary electrons from the cavity's surface material and its shape. Numerical analysis using the TRACK3P solver from the SLAC ACE3P suite of codes [52] revealed that multipacting appears at the waist area of the cavity between the cavity's wall and the capacitive plates at a deflecting voltage of about $0.1 \mathrm{MV}$ with an electron impact energy up to $1500 \mathrm{eV}$ (Fig. 6). The number of electrons with energy above $100 \mathrm{eV}$ indicates that
TABLE II. Properties of niobium $(\mathrm{Nb})$ and titanium ( $\mathrm{Ti})$ at room temperature.

\begin{tabular}{lcccc}
\hline \hline & $\begin{array}{c}\text { Density } \\
{\left[\mathrm{kg} / \mathrm{m}^{3}\right]}\end{array}$ & $\begin{array}{c}\text { Modulus } \\
{[\mathrm{GPa}]}\end{array}$ & $\begin{array}{c}\text { Poisson's } \\
\text { ratio }\end{array}$ & $\begin{array}{c}\text { Yield strength } \\
{[\mathrm{MPa}]}\end{array}$ \\
\hline $\mathrm{Nb}$ & 8570 & 103 & 0.38 & 75 \\
$\mathrm{Ti}$ & 4510 & 102 & 0.34 & $>276$ \\
\hline \hline
\end{tabular}



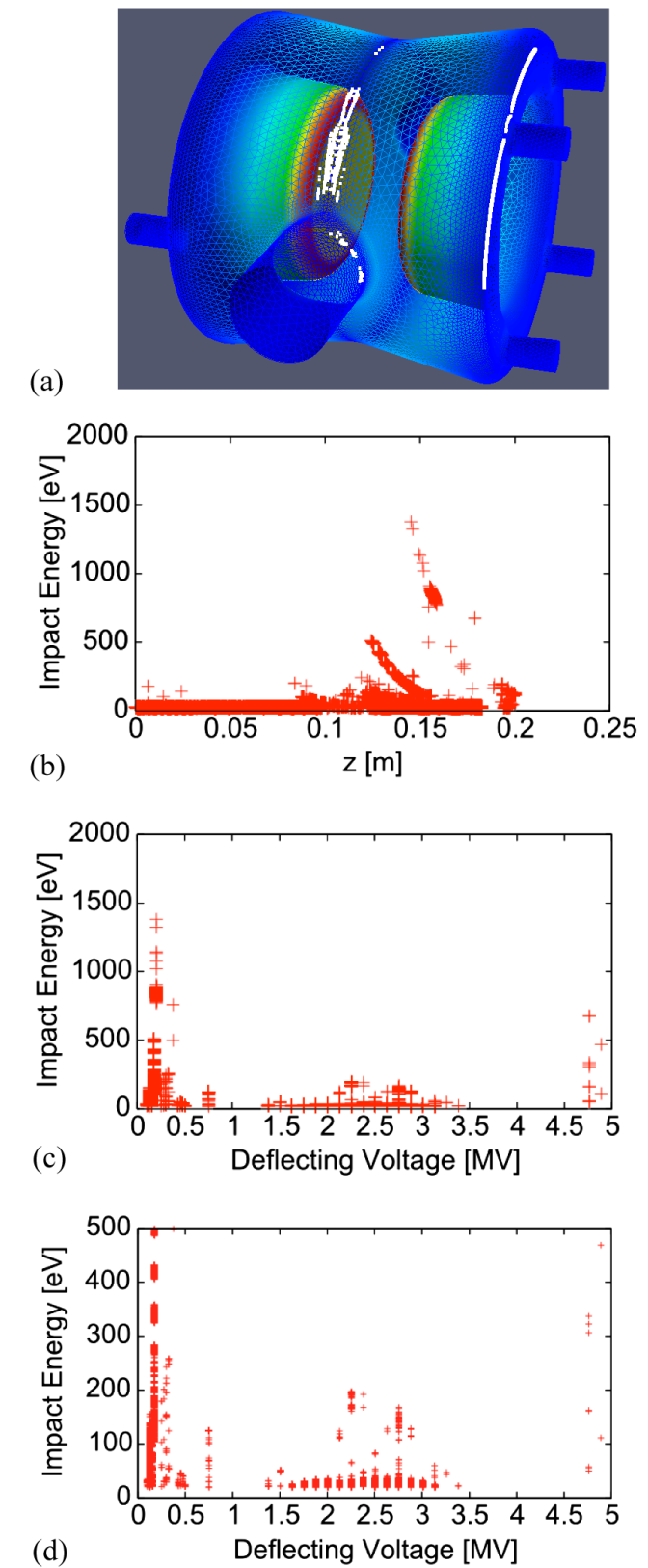

FIG. 6. Multipacting studies performed for the DQWCC with TRACK3P: (a) Potential multipacting sites on the cavity's geometry are shown as white spots. (b) Electron impact energy along the vertical direction at $0.1 \mathrm{MV}$ kick, with a maximum value of $1500 \mathrm{eV}$. (c) Electron impact energy for different deflecting voltage values. (d) Electron impact energy for different deflecting voltage values with impact energy below $500 \mathrm{eV}$.

multipacting might occur at low deflecting voltage and a 2-3 MV deflecting voltage.

\section{CAVITY FABRICATION AND MEASUREMENTS AT ROOM TEMPERATURE}

\section{A. Fabricating and processing the cavity}

The cavity body was fabricated by Niowave, Inc., from $4 \mathrm{~mm}$ niobium sheets using aluminum dies that then were

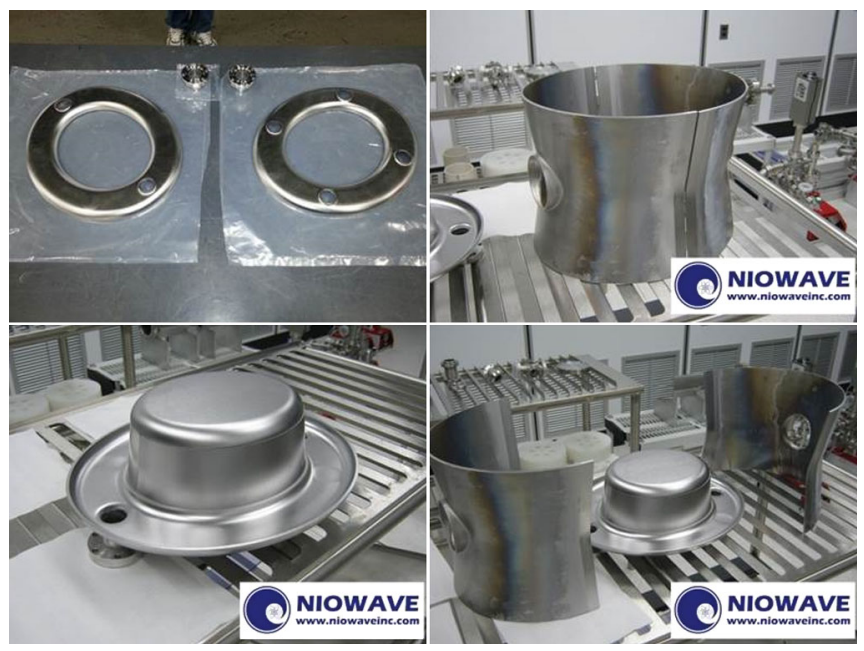

FIG. 7. Fabricating the cavity's body. Top left: top and bottom caps. Top right: outer tube. Bottom left: capacitive plate welded to the inner tube and cap. Bottom right: parts before welding.

electron beam welded together. Figure 7 shows the parts of the cavity body before welding. 2.8-mm-thick niobium tubes, with an 84-mm inner diameter for beam pipes and a 28-mm inner diameter for the FPC, PU, and HOM ports, were electron beam welded to the cavity body. The conflat flanges were brazed to the tubes before welding. Machining tolerances were not specified as the resonance frequency was not critical for the PoP cavity.

After welding, the cavity was chemically treated with a $1: 1: 2$ buffered chemical polish (BCP) solution of $\mathrm{HF}$ (49\% wt), $\mathrm{HNO}_{3}\left(69 \% \mathrm{wt}\right.$ ), and $\mathrm{H}_{3} \mathrm{PO}_{4}(85 \% \mathrm{wt})$ to etch $150 \mu \mathrm{m}$ of the inner niobium's surface. Once the cavity was received at BNL, it was inspected, visually, then checked for leaks, and finally baked for $10 \mathrm{~h}$ at $600^{\circ} \mathrm{C}$ in a vacuum oven. Thereafter, the measured resonant frequency was 403.3117 MHz. The cavity's quality factor at room temperature was 5400, in agreement with our results simulating niobium with an electric conductivity of $6.2 \times 10^{6} /(\Omega \mathrm{m})$ at room temperature. The cavity then was shipped back to Niowave for another light BCP (removing $30 \mu \mathrm{m}$ material) and a high-pressure rinse (HPR) with deionized ultrapure water. Then, it was shipped to BNL for assembly and cryogenic testing.

After the first cold test, ANL undertook further surface treatment. First, the cavity underwent an ultrasonic cleaning, which improved significantly the brightness of the cavity's outer surface. Then, the cavity was etched with $\mathrm{BCP}$ to remove a further $40 \mu \mathrm{m}$ layer. After that, the cavity was rinsed with distilled water, and ultrasonically degreased with a $2 \%$ Liquinox solvent; another rinsing in a bath of water followed this. Finally, the cavity went through another HPR with deionized water at a pressure of 1200 psi. The cavity then was shipped back to BNL for a second cryogenic test after baking for an additional $24 \mathrm{~h}$ at $120^{\circ} \mathrm{C}$ with the cavity under vacuum. 


\section{B. Measurements at room temperature}

Measurements at room temperature can help us to understand how the cavity might change during its fabrication and surface treatment. This data helps us to better specify the quality control steps for the SPS cavities. The thickness of the cavity was verified using an ultrasonic thickness detector with sensitivity of $0.01 \mathrm{~mm}$, and accuracy of $0.03 \mathrm{~mm}$. Starting with 4-mm-thick niobium, after one heavy BCP at $150 \mu \mathrm{m}$, and two light BCPs at 30 and $40 \mu \mathrm{m}$, respectively, the thickness was expected to be $3.78 \mathrm{~mm}$. We chose 52 points on the cavity's outer surface; the measured thickness was $3.92 \mathrm{~mm}$, with a standard deviation of $0.08 \mathrm{~mm}$. Thus, the cavity thickness was $140 \pm 80 \mu \mathrm{m}$ thicker than expected, indicating that insufficient material was removed during chemical etching.

The cavity's profile was measured using a laser tracker with an accuracy of $0.2 \mathrm{~mm}$. For this measurement, we used the flanges of the beam pipes. The two capacitive plates of the cavity were found to be tilted $0.21^{\circ}$ with respect to the center beam line. The bottom cap on the four-port side was titled $0.29^{\circ}$, while the top cap on the two-port side was tilted $0.63^{\circ}$. All the tilts are in the same direction.

We explored the field profile of fundamental mode using a bead-pulling setup [53]. The measurements were taken along the beam axis, and $35 \mathrm{~mm}$ vertically away from it, in the direction that the bead was moving in parallel to the beam axis and $7 \mathrm{~mm}$ away from the two-port top cap. We employed a Micarta dielectric bead (4 mm radius, $1.5-\mathrm{mm}-$ thick cylindrical bead) that measures the electric field's profile. The field profiles we measured are shown in Fig. 8. The measured results with bead pulling along the axis are consistent with the results of simulations. The $35 \mathrm{~mm}$ vertically off axis showed us two peaks, encircled in Fig. 8, a slight distance away from the simulation results; we explained this as due to the tilting of the two capacitive plates, as detected in the laser tracker's profile measurements.

\section{COLD TEST}

\section{A. Cryogenic test preparation}

The cavity was tested in a small vertical test facility (SVTF) at BNL. A $360 \mathrm{~W} 4 \mathrm{~K}$ refrigerator and a liquid ring pump were used to reach $1.9 \mathrm{~K}$. The cryogenic system can handle a $100 \mathrm{~W}$ heat load. A $200 \mathrm{~W}$ OPHIR rf power amplifier was used to power the cavity. A low-level rf phase lock loop was made to lock the frequency of the rf signal generator to the cavity's resonant frequency during the cryogenic test for both the $\mathrm{CW}$ mode and the pulsed mode. Six CERNOX temperature sensors were mounted onto the crab cavity; four of them are labeled in Fig. 9. Sensors 2 and 3 were placed in regions of high magnetic field. Sensors 1 and 4 were placed on the flanges of the beam pipe to monitor the rf losses on the niobium-film-coated stainless-steel flanges. Sensor 1 also is used to ensure that
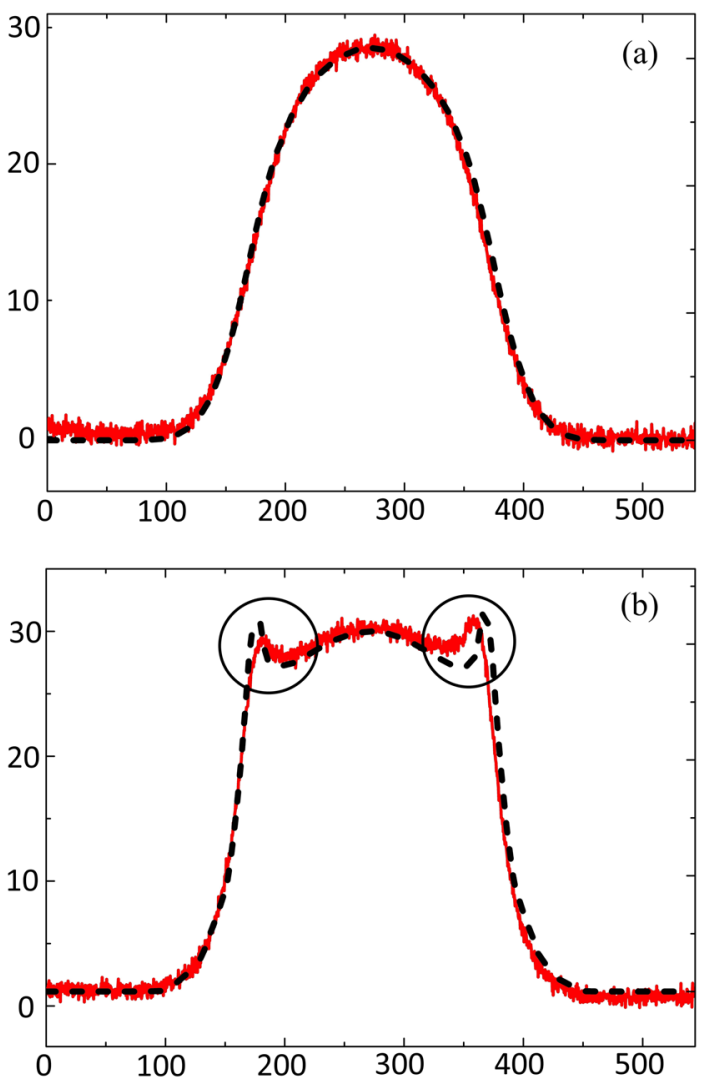

FIG. 8. Bead-pulling measurements using Micarta bead: (a) along the beam axis; (b) $35 \mathrm{~mm}$ vertically away from the beam axis. The $x$ axis represents, in $\mathrm{mm}$, the position along the beam axis from one beam port to the other one; the $y$ axis represents the phase difference in degrees. The black dots are the simulation field results, and the red curves are the results of the measurements.

the entire cavity is covered by liquid helium during the test. We developed a LabVIEW program to record the temperature every second.

For the FPC probe, we chose a hook-shaped coupler, the configuration of which is shown on the right of Fig. 9. The FPC was set up to provide $Q_{\text {ext }}$ of $2.9 \times 10^{8}$ to $5.4 \times 10^{10}$ with $20 \mathrm{~mm}$ travel distance. Figure 10 illustrates the dependence of the external $Q$ factor on the hook's position. The nominal penetration of the FPC was set as $21.2 \mathrm{~mm}$ away from the cavity's inner surface, as indicated in Fig. 9. The corresponding $Q_{\text {ext }}$ is $4.0 \times 10^{9}$. The motion of the FPC is controlled by a stepper motor mounted on the dewar's top plate and connected to the FPC via a gear box, a drive shaft, and an isosceles linkage to transfer vertical motion into a horizontal one.

A copper antenna is used as a rf pickup probe (shown in the top left corner of Fig. 9), with its position set at $20.7 \mathrm{~mm}$ away from the cavity's inner surface, corresponding to $Q_{\text {ext }}$ of $1.0 \times 10^{11}$. The error in assembly was controlled to less than $0.5 \mathrm{~mm}$, corresponding to a $Q_{\text {ext }}$ uncertainty of $8.8 \times$ $10^{10}$ to $1.2 \times 10^{11}$. 


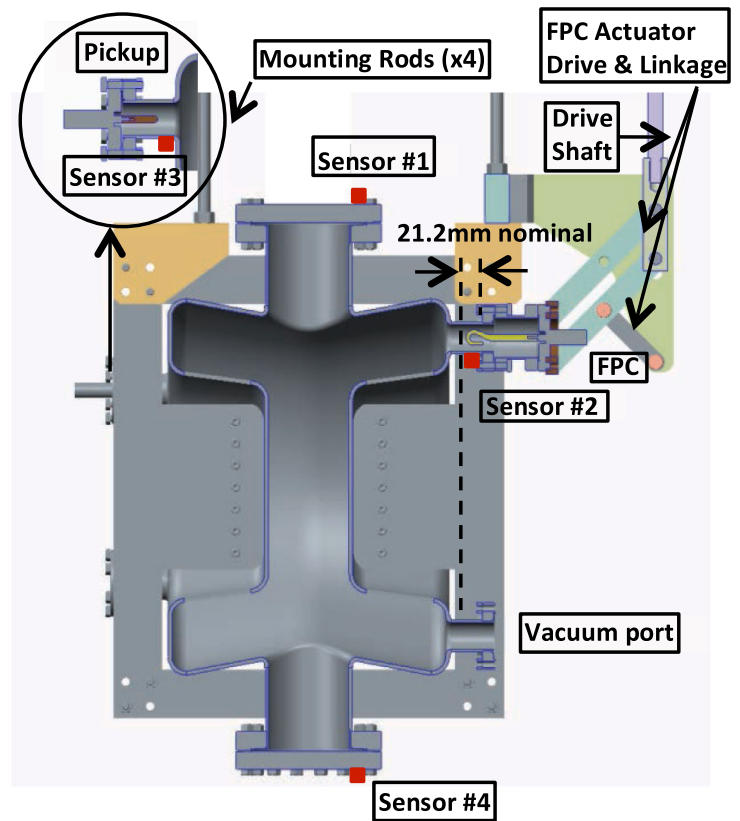

FIG. 9. Configuration of the couplers and the temperature sensors.

Two beam pipe ports were sealed with niobium-plated flanges. With an assumed surface resistance of the niobium thin film of $20 \mathrm{n} \Omega$ during the cold test, the quality factor caused by the power loss on these two flanges is $3.0 \times 10^{15}$. Three small ports that were not used during this test were sealed with copper-disk gaskets with a small venting hole in the gasket's center. The quality factor corresponding to the power loss on these gaskets is $1.1 \times 10^{11}$. The power loss on the FPC copper hook in its nominal position with a stainless steel feedthrough had an external quality factor of $4.5 \times 10^{10}$, and, for the pickup copper antenna with stainless steel feedthrough, it is $2.9 \times 10^{11}$.

The measured residual magnetic field around the cavity in the dewar was $1.2 \mu \mathrm{T}$, i.e., close to the shielding requirement in the LHC tunnel of $1 \mu \mathrm{T}$. The residual magnetic field induced residual surface resistance was $2.3 \mathrm{n} \Omega[51]$.

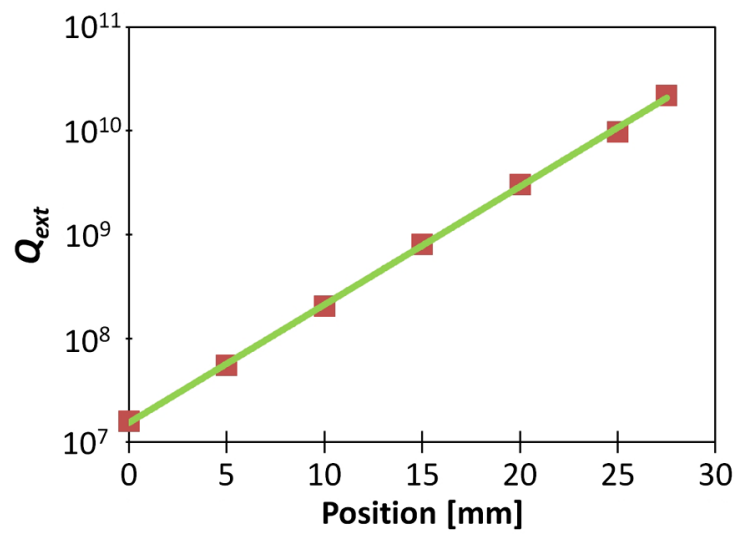

FIG. 10. $Q_{\text {ext }}$ versus position of the FPC hook.

\section{B. Cryogenic testing and analysis}

The first cryogenic test was carried out in June 2013. Figure 11 shows rigging of the cavity into the dewar, and the dewar with cavity inside the SVTF. We encountered multipacting in the deflecting voltage range between 0.07 and $0.16 \mathrm{MV}$, consistent with the multipacting analysis presented in Fig. 6. It was quickly conditioned during the first field ramp up, and never observed afterwards. $Q_{0}$ was limited to below $3 \times 10^{8}$, even at the low field level, and did not improve after cooling from 4.3 to $1.9 \mathrm{~K}$. Heating was observed on the flanges of the beam pipe (Sensors 1 and 4 in Fig. 9) in correlation with the decrease in $Q_{0}$, which indicated the poor quality of the niobium coating. The cavity reached a maximum deflecting voltage of only 1.34 MV, limited by the rf's power amplifier.

The second cryogenic test was performed in November 2013 after additionally treating the cavity at ANL as described above. With a $1.9 \mathrm{~K}$ bath temperature, as the rf power was increased, the $Q_{0}$ started to degrade at 2.0 MV, associated with high radiation due to field emission, reaching its peak of $864 \mathrm{mR} / \mathrm{h}$ at $3.0 \mathrm{MV}$. The $Q_{0}$ recovered after about $30 \mathrm{~min}$ of $\mathrm{rf}$ conditioning, as shown in Fig. 12. The radiation level fell below $15 \mathrm{mR} / \mathrm{h}$. The highest voltage reached during the test was $4.6 \mathrm{MV}$ in the $\mathrm{CW}$ mode, limited by quench, and also shown in Fig. 12. This conditioning also might be associated with multipacting, since the simulations showed a multipacting band at 2-3 MV.

During the test, we observed a rise in temperature on the flanges of both beam pipes (sensors 1 and 4 in Fig. 9) and the pickup port blending area (sensors 3 in Fig. 9).

Figure 13 shows the results from measuring the quality factor measurement after conditioning. At a liquid-helium bath temperature of $4.3 \mathrm{~K}$, the measured $Q_{0}$ fell from $1.2 \times$ $10^{9}$ to $4.4 \times 10^{8}$ with the deflecting voltage increasing from 0.1 to $2.6 \mathrm{MV}$. However, the curve of the measurement of declining power did not follow the measured curve of increasing power due to the residual stored heat from the high power. The measured $Q_{0}$ at $1.9 \mathrm{~K}$ ranged from
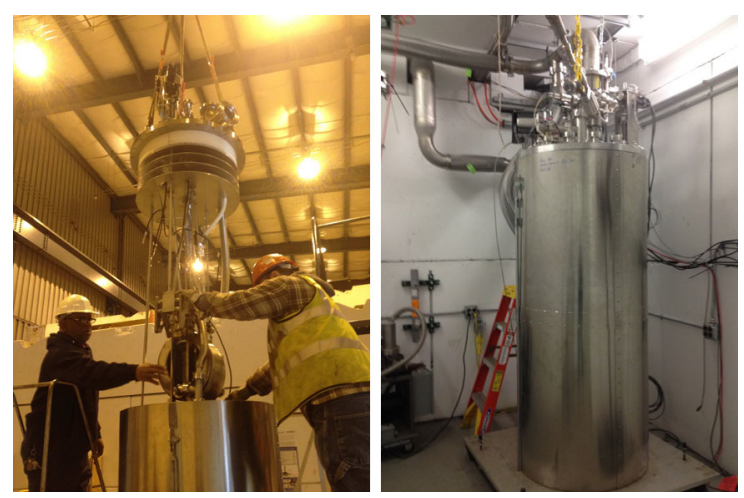

FIG. 11. Left: rigging the cavity into the dewar. Right: the dewar with the cavity inside the SVTF. 


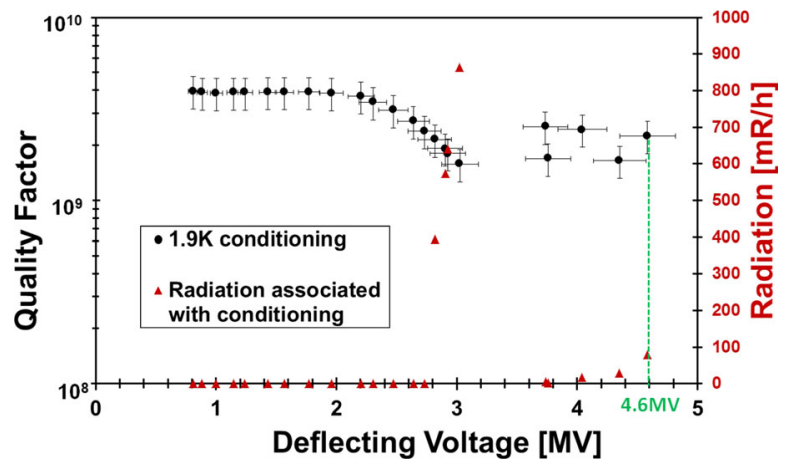

FIG. 12. Conditioning of the DQWCC at the helium bath's temperature of $1.9 \mathrm{~K}$. The black dots represent the quality factor and red triangles correspond to the associated radiation level. The cavity was rf-conditioned at the deflecting voltage of 3.0 MV for about $0.5 \mathrm{~h}$. High radiation was associated with the field emission. After conditioning, the deflecting voltage jumped to 3.8 MV and eventually reached 4.6 MV. This conditioning also might be associated with multipacting, since the simulations showed a multipacting band at 2-3 MV.

$3.0 \times 10^{9}$ to $4.0 \times 10^{9}$. In the $\mathrm{CW}$ mode, the temperature of the beam pipe's flanges rose, causing the degradation of $Q_{0}$ starting at around 3.3 MV. The plots in Fig. 13 illustrate thermal hysteresis due to the heating of the beam pipe's
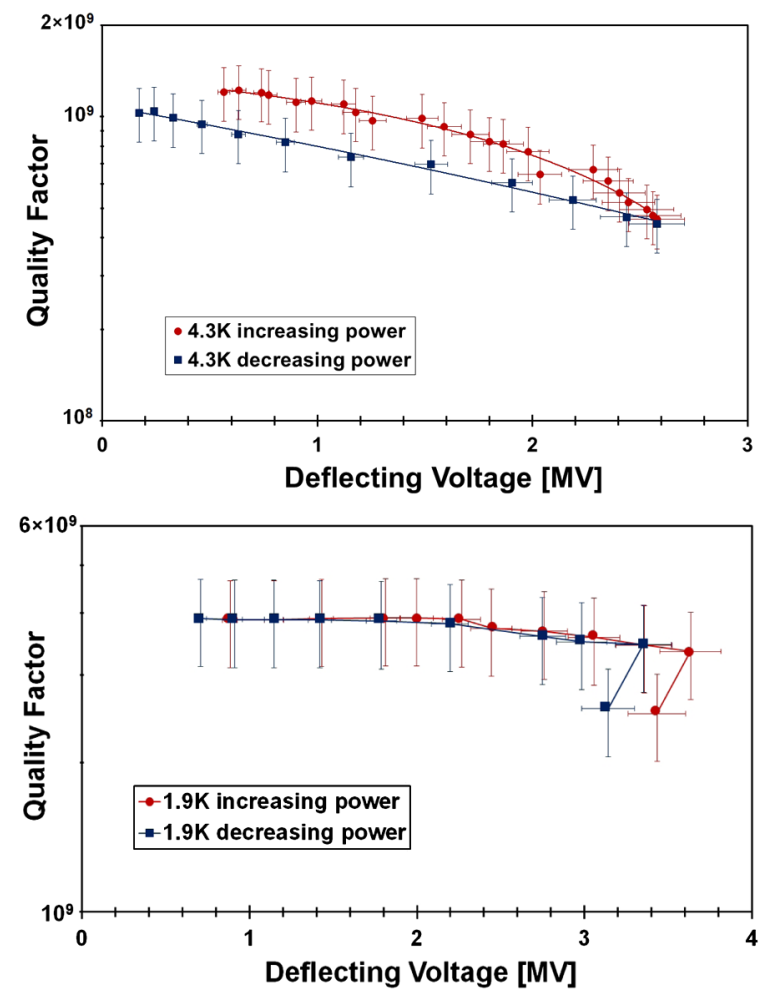

FIG. 13. Cavity quality factor at $4.3 \mathrm{~K}$ (top), and $1.9 \mathrm{~K}$ (bottom) bath temperatures in the $\mathrm{CW}$ mode. The data illustrate thermal hysteresis associated with heating the beam pipe's flanges. The red curves were taken with rf power ramping up, and the black curves were taken with its ramping down. flanges. The temperature increase also was observed at the pickup port's blending area.

In an attempt to reduce the heating on these flanges, the cavity was further tested in a pulsed mode. The highest voltage reached was $4.5 \mathrm{MV}$, limited by quench, consistent with the test results in the CW mode at 4.6 MV. The cavity quenched at a peak magnetic field of about $129.3 \mathrm{mT}$, and a peak electric field of about $49.4 \mathrm{MV} / \mathrm{m}$.

The surface resistance at low field is $60.0 \mathrm{n} \Omega$ at $4.3 \mathrm{~K}$, and $22.1 \mathrm{n} \Omega$ at $1.9 \mathrm{~K}$. The results of this measurement were fitted using the following expression [51,54]:

$$
R_{s}[\mathrm{n} \Omega]=\frac{A}{T} \ln \left(\frac{4 k T}{h f}\right) e^{\left(-\frac{\Delta}{k T}\right)}+R_{\text {res }} .
$$

The fitting parameters are $R_{\text {res }}=21 \mathrm{n} \Omega, \Delta / k T_{c}=1.87$, and $A=1212.77 \mathrm{n} \Omega \mathrm{K}$. Figure 14 compares the measured data points and the fitting curve. We suspect that high residual resistance partly is associated with losses in the thin niobium coating of the stainless steel flanges on the beam pipes. The temperature rise on the flanges implies that the quality of the thin film was not well controlled. Another possible reason for the high residual resistance is insufficient etching during $\mathrm{BCP}$, a conclusion which is corroborated by the measurement of the cavity wall's thickness.

Lorentz-force detuning is an effect of deforming the cavity's shape brought by radiation pressure, with the magnetic field causing pressure outward of the cavity and electric field causing pressure inward. It causes a frequency shift of the cavity's electromagnetic field. The Lorentz force detuning coefficient of the DQWCC is $-206 \mathrm{~Hz} / \mathrm{MV}^{2}$, calculated from the $\mathrm{CW}$ measurement at $1.9 \mathrm{~K}$. The sensitivity of the cavity's frequency to the pressure of the helium bath was measured during the cavity's cool down. The resonance frequency changed from $403.667 \mathrm{MHz}$ at $4.3 \mathrm{~K}$ to $403.930 \mathrm{MHz}$ at $1.9 \mathrm{~K}$. The pressure sensitivity was $336 \mathrm{~Hz} /$ Torr.

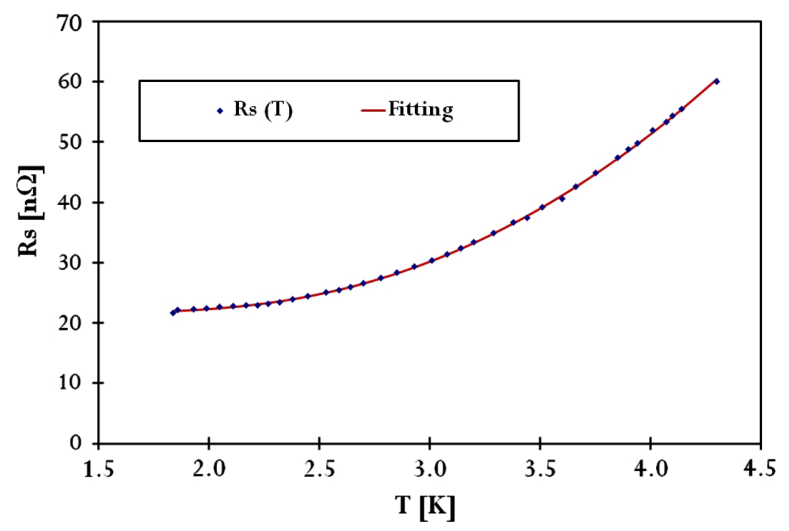

FIG. 14. Surface resistance versus cavity temperature during the cool down of the cavity from 4.3 to $1.9 \mathrm{~K}$. The data points are taken at peak rf fields lower than $23.6 \mathrm{mT}$. The dots are the measured data points; the red curve is fitted using Eq. (1). 


\section{CONCLUSIONS}

We proposed using a double quarter wave resonator as a compact crab cavity for the LHC luminosity upgrade. We designed and fabricated a proof-of-principle cavity to validate that a cavity of such a complicated shape can deliver a deflecting voltage over the required 3.34 MV. A special stiffening frame was designed and implemented for the PoP cavity to relieve mechanical stresses on it and to bring it in compliance with the CERN safety code. We measured the cavity's thickness using an ultrasonic thickness detector; it was $140 \mu \mathrm{m}$ thicker than expected, indicating that insufficient material was removed during chemical etching. Using a laser tracker to measure the cavity's profile revealed that the top and bottom caps, and two capacitive plates, are tilted in the same direction with respect to the center beam line. Bead-pulling measurements using a dielectric bead moving along the beam's axis is consistent with the simulated profile of the electric field. Similar measurements with the bead moving $35 \mathrm{~mm}$ vertically off axis showed two peaks that depart slightly from the results of the simulation, which could be explained by the tilting of the two capacitive plates detected in the measurement with the laser tracker. A multipacting zone was found at a deflecting voltage of approximately $0.1 \mathrm{MV}$ during the first cold test, as predicted by our numerical analysis, and was conditioned easily. The cavity did not show any multipacting in this voltage range during the second cold test. During BNL's cryogenic tests, the cavity achieved a deflecting voltage of $4.6 \mathrm{MV}$, with a quality factor higher than $3.0 \times 10^{9}$. Possible reasons for the relatively low quality factor are associated with (i) insufficient BCP etching, and (ii) the poor quality of the niobium coating on the stainless steel flanges of the beam pipes.

With the proof-of-principle DQWCC exceeding the design voltage by a satisfactory margin, we are proceeding with designing and fabricating two fully dressed prototype cavities. After verifying the cavities' performance in vertical tests, they will be installed in SPS for testing with the beam as the next step toward implementing the crabcavity scheme in the HL-LHC.

The DQW design can be applied to other particle accelerators requiring deflecting or crab cavities, in particular to BNL's future electrohadron collider, eRHIC [55]. In eRHIC, the 5- to 8-cm-long ion bunches will collide with electrons at a crossing angle of $4 \mathrm{mrad}$. This would require a low crabbing frequency $f_{0}$ that currently is set at $225 \mathrm{MHz}$. The DQWCC is well suited for such low frequency application with its reasonable geometrical size $[42,56]$.

\section{ACKNOWLEDGEMENTS}

The authors would like to acknowledge Niowave, Inc., for fabricating this cavity. The authors thank S. Gerbick, M. P. Kelly, R. C. Murphy, P. N. Ostroumov, and T. C. Reid at ANL for the surface treatments, and BNL's D. Beavis, P. P. Cirnigliaro, C. Degen, H. Dorr, A. Etkin, R. C. Karol, R. Kellermann, E. T. Lessard, G. T. McIntyre, J. Moore, S. P. Pontieri, R. Porqueddu, T. Seda, L. P. Snydstrup, T. Tallerico, R. Than, and J. E. Tuozzolo at BNL for help with the cryogenic setup and tests. The work partly was supported by the U.S. DOE through Brookhaven Science Associates, LLC under Contract No. DE-AC02-98CH10886 with the U.S. LHC Accelerator Research Program (LARP), and by the EU FP7 HiLumi LHC Grant Agreement No. 284404. This research used the resources of the National Energy Research Scientific Computing Center (NERSC), which is supported by the U.S. DOE under Contract No. DE-AC02$05 \mathrm{CH} 11231$.

[1] S. Fu and T. Kato, RF-chopper for the JHF proton linac, Nucl. Instrum. Methods Phys. Res., Sect. A 440, 296 (2000).

[2] A. Aleksandrov, in Proceedings of the 25th International Linear Accelerator Conference, LINAC-2010, Tsukuba, Japan (KEK, Tsukuba, Japan, 2010), p. 689 [http:// accelconf.web.cern.ch/accelconf/LINAC2010/papers/we104 .pdf].

[3] T. Maruta and M. Ikegami, Longitudinal beam halo measurement with an RF chopper system, Nucl. Instrum. Methods Phys. Res., Sect. A 728, 126 (2013).

[4] H. Hahn and H. J. Halama, Design of the deflector for the rf beam separator at the Brookhaven AGS, Rev. Sci. Instrum. 36, 1788 (1965).

[5] A. Citron, G. Dammertz, M. Grundner et al., First operation of a superconducting rf-particle separator, Nucl. Instrum. Methods 155, 93 (1978).

[6] C. Leemann and C. G. Yao, in Proceedings of the Linear Accelerator Conference 1990, Albuquerque, NM, p. 232, http://accelconf.web.cern.ch/accelconf/190/papers/ mo465.pdf.

[7] R. Tomas, Overview of the Compact Linear Collider, Phys. Rev. ST Accel. Beams 13, 014801 (2010).

[8] M. Aicheler, P. Burrows, M. Draper et al., Report No. CERN-2012-007, 2012 [http://dx.doi.org/10.5170/ CERN-2012-007].

[9] M. Katoh, Ultra-short pulses of synchrotron radiation on storage rings, Jpn. J. Appl. Phys. 38, L547 (1999).

[10] P. Emma, R. Iverson, P. Krejcik et al., in Proceedings of the 19th Particle Accelerator Conference, Chicago, IL, 2001 (IEEE, Piscataway, NJ, 2001), p. 4038 [http://accelconf .web.cern.ch/AccelConf/p01/PAPERS/FPAH165.PDF].

[11] Z. Huang, A. Brachmann, F.-J. Decker et al., Measurements of the linac coherent light source laser heater and its impact on the X-ray free-electron laser performance, Phys. Rev. ST Accel. Beams 13, 020703 (2010).

[12] P. Emma, J. Frisch, and P. Krejcik, Report No. LCLS-TN-0012, 2000,http://www-ssrl.slac.stanford.edu/lcls/technotes/ lcls-tn-00-12.pdf.

[13] D. Alesini, G. D. Pirro, L. Ficcadenti et al., RF deflector design and measurements for the longitudinal and transverse phase space characterization at SPARC, Nucl. Instrum. Methods Phys. Res., Sect. A 568, 488 (2006). 
[14] A. Falone, H. Fitze, R. Ischebeck et al., in Proceedings of the 23rd Particle Accelerator Conference, Vancouver, Canada, 2009 (IEEE, Piscataway, NJ, 2009), p. 2012 [http://accelconf.web.cern.ch/accelconf/pac2009/papers/ we 5pfp012.pdf].

[15] H. Tomizawa, H. Hanaki, and T. Ishikawa, in Proceedings of the 29th International Free Electron Laser Conference, Novosibirsk, Russia (BINP, Novosibirsk, 2007), p. 472 [http:// accelconf.web.cern.ch/AccelConf/f07/PAPERS/WEPPH053 .PDF].

[16] Y. Ding, C. Behrens, P. Emma et al., Femtosecond x-ray pulse temporal characterization in free-electron lasers using a transverse deflector, Phys. Rev. ST Accel. Beams 14, 120701 (2011).

[17] R. K. Li, P. Musumeci, H. A. Bender et al., Imaging single electrons to enable the generation of ultrashort beams for single-shot femtosecond relativistic electron diffraction, J. Appl. Phys. 110, 074512 (2011).

[18] V. A. Dolgashev and J. Wang, RF design of X-band RF deflector for femtosecond diagnostics of LCLS electron beam, AIP Conf. Proc. 1507, 682 (2012).

[19] K. Akai and M. Tigner, in Handbook of Accelerator Physics and Engineering. 3rd ed.,edited by A. W. Chao, K. H. Mess, M. Tigner, and F. Zimmermann (World Scientific, Singapore, 2006), p. 617.

[20] R. B. Palmer, Report No. SLAC-PUB-4707, 1988, http:// www.slac.stanford.edu/cgi-wrap/getdoc/slac-pub-4707.pdf.

[21] T. Abe, K. Akai, M. Akemoto et al., in Proceedings of the 22nd Particle Accelerator Conference, PAC-2007, Albuquerque, NM (IEEE, New York, 2007), p. 27 [http://accelconf.web.cern.ch/AccelConf/p07/PAPERS/ MOZAKI01.PDF].

[22] L. Rossi, S. Stavrev, and A. Szeberenyi, Report No. CERN-ACC-2013-022, 2013.

[23] Z. Li, L. Xiao, C. Ng et al., in Proceedings of the International Particle Accelerator Conference, Kyoto, Japan, 2010 (ICR, Kyoto, 2010), p. 504 [http://accelconf .web.cern.ch/AccelConf/IPAC10/papers/mopec022.pdf].

[24] R. Calaga, in Proceedings of 15th International Conference on RF Superconductivity, Chicago, 2011, p. 988, http://accelconf.web.cern.ch/accelconf/SRF2011/ papers/friob05.pdf.

[25] R. Calaga, S. Belomestnykh, I. Ben-Zvi et al., in Proceedings of the 3rd International Particle Accelerator Conference, New Orleans, LA, 2012 (IEEE, Piscataway, NJ, 2012), p. 2260 [http://accelconf.web.cern.ch/accelconf/IPAC2012/ papers/weppc027.pdf].

[26] R. Calaga, S. Belomestnykh, I. Ben-Zvi et al., in Proceedings of the 4th International Particle Accelerator Conference, IPAC-2013, Shanghai, China (JACoW, Shanghai, China, 2013), p. 2408 [http://accelconf.web .cern.ch/accelconf/IPAC2013/papers/wepwo047.pdf].

[27] S. U.D. Silva and J.R. Delayen, Cryogenic test of a proof-of-principle superconducting rf-dipole deflecting and crabbing cavity, Phys. Rev. ST Accel. Beams 16, 082001 (2013).

[28] B. P. Xiao, S. Belomestnykh, I. Ben-Zvi et al., in Proceedings of 16th International Conference on RF Superconductivity, Paris, France, 2013, p. 1002, http://accelconf .web.cern.ch/AccelConf/SRF2013/papers/thp043.pdf.
[29] G. Burt, B. Hall, C. Lingwood et al., in Proceedings of the 4th International Particle Accelerator Conference, IPAC2013, Shanghai, China (JACoW, Shanghai, China, 2013), p. 2420 [http://accelconf.web.cern.ch/accelconf/IPAC2013/ papers/wepwo051.pdf].

[30] I. Ben-Zvi and J. M. Brennan, The quarter wave resonator as a superconducting linac element, Nucl. Instrum. Methods Phys. Res. 212, 73 (1983).

[31] W. Hartung, J. Bierwagen, S. Bricker et al., in Proceedings of the 24th Linear Accelerator Conference, Victoria, British Columbia, Canada, 2008, p. 854, http://accelconf.web.cern .ch/AccelConf/LINAC08/papers/thp033.pdf.

[32] G. Olry, S. Bousson, T. Junquera et al., in Proceedings of the 23rd International Linac Conference, LINAC-2006, Knoxville, TN, 2006 (JACoW, Knoxville, TN, 2006), p. 698 [http://accelconf.web.cern.ch/accelconf/106/PAPERS/ THP052.PDF].

[33] A. Roy, in Proceedings of the 13th International workshop on RF Superconductivity, Beijing, China, 2007, p. 24, http:// accelconf.web.cern.ch/accelconf/srf2007/PAPERS/MO303 .pdf.

[34] R. E. Laxdal, K. Fong, M. Laverty et al., Recent progress in the superconducting rf program at TRIUMF/ISAC, Physica C (Amsterdam) 441, 13 (2006).

[35] M. P. Kelly, J. D. Fuerst, S. Gerbick et al., in Proceedings of the 24th Linear Accelerator Conference, Victoria, British Columbia, Canada, p. 836, http://accelconf.web .cern.ch/accelconf/LINAC08/papers/thp025.pdf.

[36] C. H. Boulware, T. L. Grimm, I. Ben-Zvi et al., in Proceedings of the 3rd International Particle Accelerator Conference, New Orleans, LA, 2012 (IEEE, Piscataway, NJ, 2012), p. 2405 [http://accelconf.web.cern.ch/AccelConf/ IPAC2012/papers/weppc083.pdf].

[37] Q. Wu, S. Belomestnykh, I. Ben-Zvi et al., in Proceedings of the 16th International Conference on RF Superconductivity, Cite Internationale Universitaire, Paris, France, 2013, p. 969, http://accelconf.web.cern.ch/AccelConf/SRF2013/ papers/thp031.pdf.

[38] S. Belomestnykh, I. Ben-Zvi, C. H. Boulware et al., in Proceedings of the 24th Particle Accelerator Conference, PAC-2011, New York (IEEE, New York, 2011), p. 898 [http://accelconf.web.cern.ch/AccelConf/PAC2011/papers/ tup051.pdf].

[39] J. R. Harris, K. L. Ferguson, J. W. Lewellen et al., Design and operation of a superconducting quarter-wave electron gun, Phys. Rev. ST Accel. Beams 14, 053501 (2011).

[40] J. Bisognano, R. Bosch, D. Eisert et al., in Proceedings of the 24th Particle Accelerator Conference, PAC-2011, New York (IEEE, New York, 2011), p. 2444 [http://accelconf .web.cern.ch/AccelConf/PAC2011/papers/thp176.pdf].

[41] I. Ben-Zvi, 4th LHC Crab Cavity Workshop; December 15-17, 2010; CERN, Geneva, Switzerland, 2010, http://indico.cern.ch/event/100672/session/1/contribution/52/ material/slides/1.pdf.

[42] I. Ben-Zvi, in Proceedings of 15th International Conference on RF Superconductivity, Chicago, IL, 2011, p. 637, http://accelconf.web.cern.ch/AccelConf/ SRF2011/papers/thioa04.pdf.

[43] F. L. Krawczyk, in Proceedings of the Particle Accelerator Conference, Dallas, TX, 1995 (IEEE, New York, 1995), 
p. 2361 [http://accelconf.web.cern.ch/AccelConf/p95/ ARTICLES/MPC/MPC22.PDF].

[44] J. B. García, R. Calaga, R. D. Maria et al., in Proceedings of the 3rd International Particle Accelerator Conference, New Orleans, LA, 2012 (IEEE, Piscataway, NJ, 2012), p. 1873 [http://accelconf.web.cern.ch/accelconf/IPAC2012/ papers/tuppr027.pdf].

[45] P. Baudrenghien, K. Brodzinski, R. Calaga et al., Report No. CERN-ACC-NOTE-2013-003, 2013, http://cds.cern.ch/ record/1520896/files/CERN-ACC-NOTE-2013-003.pdf? subformat=pdfa.

[46] CERN, EDMS No. 875609, 2008.

[47] CERN, EDMS No. 875606, 2008.

[48] L. Alberty, EDMS No. 1284428, 2013.

[49] B. P. Xiao, L. Alberty, S. Belomestnykh et al., in Proceedings of the 4th International Particle Accelerator Conference, IPAC-2013, Shanghai, China (JACoW, Shanghai, China, 2013), p. 2417 [http://accelconf.web.cern.ch/AccelConf/ IPAC2013/papers/wepwo050.pdf].

[50] K. M. Wilson, E.F. Daly, J. Henry et al., in Proceedings of the 20th Particle Accelerator Conference, PAC-2003, Portland, OR (IEEE, New York,
2003), p. 2866 [http://accelconf.web.cern.ch/AccelConf/ p03/PAPERS/RPAB064.PDF].

[51] H. Padamsee, J. Knobloch, and T. Hays, RF Superconductivity for Accelerators (John Wiley \& Sons, New York, 1998).

[52] K. Ko, A. Candel, L. Ge et al., in Proceedings of the 25th International Linear Accelerator Conference, LINAC-2010, Tsukuba, Japan (KEK, Tsukuba, Japan, 2010), p. 1028 [http://accelconf.web.cern.ch/accelconf/ LINAC2010/papers/fr101.pdf].

[53] C. Marques, Master's thesis, Stony Brook University, 2014.

[54] G. Ciovati, Jefferson Lab Tech Note 03-003, 2003, http:// tnweb.jlab.org/tn/2003/03-003.pdf.

[55] S. Belomestnykh, I. Ben-Zvi, C. Brutus et al., in Proceedings of the 3rd International Particle Accelerator Conference, New Orleans, LA, 2012 (IEEE, Piscataway, NJ, 2012), p. 2474 [http://accelconf.web.cern.ch/accelconf/IPAC2012/ papers/weppc109.pdf].

[56] Q. Wu, S. Belomestnykh, and I. Ben-Zvi, in Proceedings of 15th International Conference on RF Superconductivity, Chicago, IL, 2011, p. 707, http://accelconf.web.cern.ch/ AccelConf/SRF2011/papers/thpo007.pdf. 